\title{
- Posse responsável de cães no Município de Botucatu-SP: realidades e desafios
}

\section{- Canine responsible ownership in Botucatu city, $S P$ : realities and chalengers}

\section{- Posesión responsable de perros en la Municipalidad de Botucatu-SP: realidades y desafios}

" Luiz Carlos de Souza ${ }^{1}$ - CRMV-SP - n' 1094

José Rafael Modolo ${ }^{2}$ - CRMV-SP - n 2180

Carlos Roberto Padovani ${ }^{3}$ - Matemático

André de Oliveira Mendonça ${ }^{4}$ - CRMV-SP - no 11399

Ana Lúcia Scarelli Lopes ${ }^{4}$ - CRMV-SP - n 09177

Wellington Borges da Silva ${ }^{4}$ - CRMV-SP $-n^{\circ} 12043$
"Faculdade de Medicina Veterinánia e Zootecnia - UNESP - Botucatu

Dept ${ }^{\circ}$ de Higiene Veterinária e Saúde Pública Caixa Postal 524-18618-000-Botucatu-SP Email-mail: higvet@frmvzunesp.br

1 Prof. Adjunto na Disciplina de Epidemiologia e Saneamento

2 Prof. Adjunto na Disciplina de Planejamento de Saúde Animal e Veterinária Preventiva

3 Prof. Titular na Disciplina de Bioestatística

4 Pós-graduandos na UNESP/FMVZ de Botucatu - Área de Vigilância Sanitária

\section{RESUMO}

Investigaram-se aspectos relacionados aos cuidados que os proprietários de cães dispensam aos seus animais, no Município de Botucatu-SP, por meio da aplicação de um inquérito. Foram entrevistadas 1168 pessoas durante a $33^{\mathrm{a}}$ campanha anual de vacinação anti-rábica. Destas, 67,98\% (794/1168) desconhecem a necessidade de aplicação de outras vacinas em seus cães, além da anti-rábica. Constatou-se que $32,11 \%$ (388/1168) dos proprietários não vermifugam seus cães anualmente e 76,89\% (898/1168) utilizam ectoparasiticidas no máximo uma vez por ano. Dos 120 proprietários que levam seus cães para defecar em vias públicas, apenas um $(0,83 \%)$ recolhe as fezes. Com relação à alimentação dos animais, 50,09\% (585/1168) são alimentados apenas com ração comercial. Os resultados revelaram que existem 187 cães para cada grupo de 100 proprietários. No que diz respeito ao serviço 


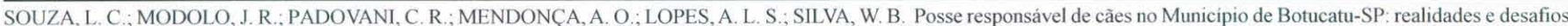

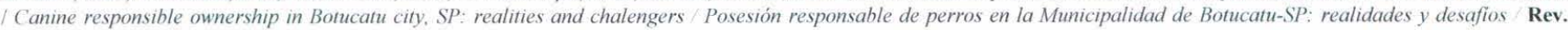
educ. contin. CRMV-SP / Continuous Education Journal CRMV-SP, São Paulo, volume 5, fascículo 2, p. 226 - $232,2002$.

\section{RESUMO}

veterinário, $56,59 \%(661 / 1168)$ dos entrevistados jamais levam seus cães para serem consultados em uma clínica veterinária, e 49,57\% (579/1168) afirmam não ter condições de pagar uma consulta. Quando perguntados sobre o gasto mensal que têm com seus cães, 44,69\% (522/1168) dos proprietários responderam que gastam menos de $\mathrm{R} \$ 20,00$ /mês. Os dados obtidos no presente trabalho indicam que a maioria dos proprietários não dispensa os cuidados mínimos necessários para a promoção da saúde e bem-estar de seus cães, o que pode trazer conseqüências também para a saúde pública. O desenvolvimento sócioeconômico do País e um processo eficiente de educação continuada em saúde que permita a internalização dos conceitos de posse responsável de animais de companhia são fatores indispensáveis para a melhoria do bem-estar animal e, por conseqüência, a da saúde pública.

Palavras-chave: Posse responsável. Saúde animal. Saúde pública. Cão.

\section{Introdução e Revisão de Literatura}

mercado de "pet shops" encontra-se em franca expansão, em nosso País. De 1995 a 2001, o setor cresceu $17 \%$ ao ano. Atualmente, existem cerca de 8 mil estabelecimentos deste ramo no Brasil e a metade está localizada no Estado de São Paulo (Jornal O Estado de São Paulo, PN2, 06/11/2001). Cerca de 27 milhões de cães, entre outros animais de companhia, são responsáveis por uma movimentação anual de 1,9 bilhão de reais apenas com alimentação (Jornal O Estado de São Paulo, B5, 17/02/2002).

Embora estes números indiquem uma preocupação crescente dos proprietários com o bem-estar de seus animais, evidenciada pelo aquecimento do mercado de "pet shops", não se sabe se retratam uma realidade para todos os níveis sociais ou se são decorrentes apenas do comportamento das classes mais privilegiadas. Também não se sabe se o nível de informação da população sobre os cuidados com a saúde de seus animais de estimação tem crescido na mesma proporção que as vendas da ração comercial, tendo em vista a escassez de trabalhos, na literatura nacional, que abordem este aspecto da criação de cães.

No presente estudo, teve-se por objetivo investigar, por meio da aplicação de um questionário, os cuidados que os proprietários têm com a saúde de seus cães, no Município de Botucatu-SP, avaliando-se até que ponto os conceitos relacionados à posse responsável de animais de companhia estão sendo incorporados à cultura local.

\section{Material e Método}

Os dados retratados no presente trabalho foram obtidos mediante aplicação de um questionário aos pro- prietários dos cães, durante a $33^{\mathrm{a}}$ campanha anual de vacinação anti-rábica, realizada no período de 27 a 31 de agosto de 2001, quando foram vacinados 16838 cães (MODOLO, J. R., comunicação pessoal). De acordo com o último censo do IBGE, o Município de Botucatu tem uma população humana estimada em 108306 habitantes (Instituto Brasileiro de Geografia e Estatística, 2000). A campanha é realizada pela área de Planejamento de Saúde Animal e Veterinária Preventiva da Faculdade de Medicina Veterinária e Zootecnia, UNESP, Botucatu, em parceria com a Secretaria Municipal da Saúde da Prefeitura local.

A seleção dos proprietários de cães, para a entrevista, foi feita por amostragem aleatória simples, tendo sido sorteados quatro postos de vacinação por dia, totalizando 20 postos de vacinação amostrados, representativos do total de 44 postos, distribuídos homogeneamente em cinco regiões da área territorial urbana do município, de $32 \mathrm{Km} 2$,com uma área de abrangência de cada posto de, em média, $0,8 \mathrm{Km} 2$. Para cada posto, foi estabelecida uma amostragem representativa mínima, de acordo com o número de cães vacinados no ano anterior (total de 14559 animais MODOLO, J. R., comunicação pessoal).

Após a vacinação dos cães, os proprietários selecionados eram convidados a responder ao questionário, cuja aplicação ficou sob responsabilidade exclusiva dos pós-graduandos da área de Vigilância Sanitária do curso de pós-graduação da Faculdade, para garantir o esclarecimento aos proprietários dos cães, interpretação das respostas, discussão das perguntas e forma de abordar os entrevistados e de conduzir adequadamente a entrevista. Ao todo, foram inquiridos 1168 proprietários.

As respostas foram compiladas e analisadas com o auxílio do programa computacional EPI-INFO 6.0. 


\section{Resultados}

De acordo com as respostas obtidas, existem 187 cães e 168 gatos para cada grupo de 100 proprietários (Figuras 1 e 2). Cerca de 50,00\% dos entrevistados utilizam apenas ração na alimentação de seus cães (Figura 3). Dos 120 proprietários que levam seus cães para defecar em via públicas, apenas um $(0,83 \%)$ recolhe as fezes (Quadro 1).

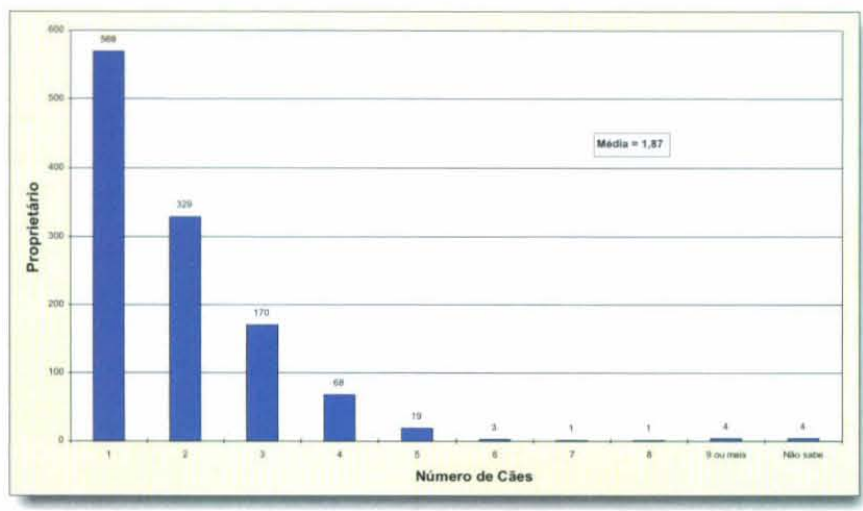

Figura 1 - Número total de cães por proprietário, de acordo com questionário respondido durante a campanha anual de vacinação anti-rábica. Botucatu. 2001

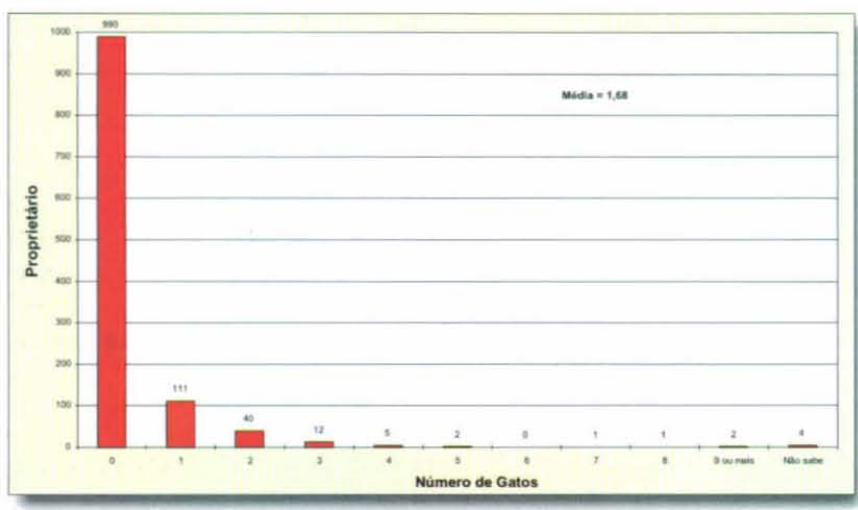

Figura 2 - Número total de gatos por proprietário de cão, de acordo com questionário respondido durante a campanha anual de vacinação anti-rábica. Botucatu. 2001.

A maior parte dos proprietários $(67,98 \%)$ não sabe que precisa vacinar seus cães com outras vacinas além da anti-rábica (Quadro 2). Dos 1168 entrevistados, $770(65,92 \%)$ afirmaram que vermifugam seus cães pelo menos uma vez por ano (Quadro 3). Apenas $10,53 \%$ dos entrevistados aplicam drogas ectoparasiticidas, nos seus cães mais de duas vezes por ano (Figura 4).

No tocante à utilização do serviço veterinário, mais da metade dos entrevistados não costuma levar seus cães a uma clínica veterinária (Quadro 4), e 49,57\%

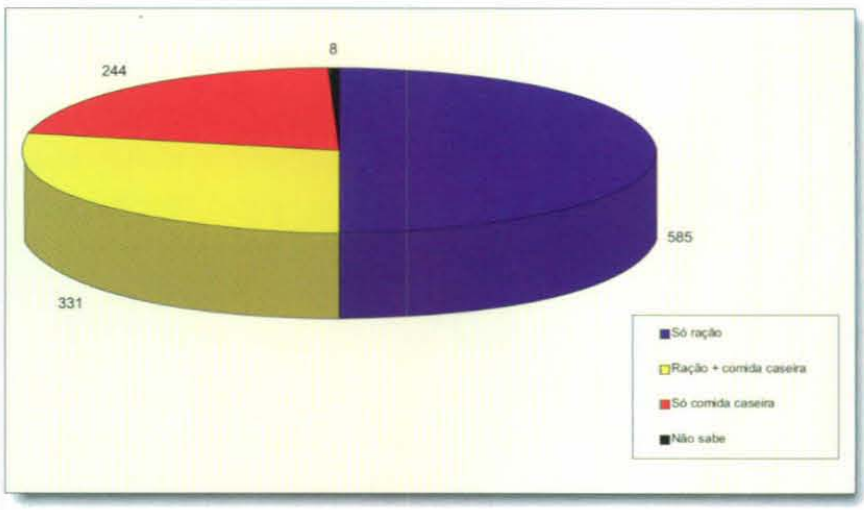

Figura 3 - Tipo de alimentação oferecida aos cães, de acordo com questionário respondido durante a campanha anual de vacinação anti-rábica. Botucatu. 2001

\begin{tabular}{|c|c|cc|c|c|}
\hline $\begin{array}{c}\text { Local de } \\
\text { defecação }\end{array}$ & Quintal & \multicolumn{2}{|c|}{ Rua } & $\begin{array}{c}\text { Não } \\
\text { sabe }\end{array}$ & Total \\
\hline & & $\begin{array}{c}\text { Proprietário } \\
\text { recolhe } \\
\text { as fezes }\end{array}$ & $\begin{array}{c}\text { Proprietário } \\
\text { não recolhe } \\
\text { as fezes }\end{array}$ & & \\
\hline$n$ & 1031 & 1 & 119 & 17 & 1168 \\
\hline$\%$ & 88,27 & 0,09 & 10,19 & 1,45 & 100,00 \\
\hline
\end{tabular}

Quadro 1 - Local de defecação dos cães, de acordo com questionário respondido durante a campanha anual de vacinação anti-rábica. Botucatu. 2001

\begin{tabular}{|l|c|c|}
\hline & $n$ & $\%$ \\
\hline Sabe que precisa vacinar & 335 & 28,68 \\
\hline Não sabe que precisa vacinar & 794 & 67,98 \\
\hline Sem resposta & 39 & 3,34 \\
\hline Total & 1168 & 100,00 \\
\hline
\end{tabular}

Quadro 2 - Número de proprietários que sabem que seus cães precisam ser vacinados com outras vacinas além da anti-rábica, de acordo com questionário respondido durante a campanha anual de vacinação anti-rábica. Botucatu. 2001.

dos proprietários afirmam não ter condições de pagar uma consulta(Quadro 5). A figura 5 ilustra o custo médio mensal que os proprietários têm com seus cães, mas $44,69 \%$ não gastam mais de R \$20,00/mês.

\section{Discussão e Conclusão}

O número médio de cães por proprietário obtido no presente trabalho é discretamente superior aos 


\begin{tabular}{|l|c|c|}
\hline & $n$ & $\%$ \\
\hline Vermifuga anualmente & 770 & 65,92 \\
\hline Não vermifuga anualmente & 375 & 32,11 \\
\hline Sem resposta & 23 & 1,97 \\
\hline Total & 1168 & 100,00 \\
\hline
\end{tabular}

Quadro 3 - Número de proprietários que costumam vermifugar seus cães pelo menos uma vez por ano, de acordo com questionário respondido durante a campanha anual de vacinação anti-rábica. Botucatu. 2001.

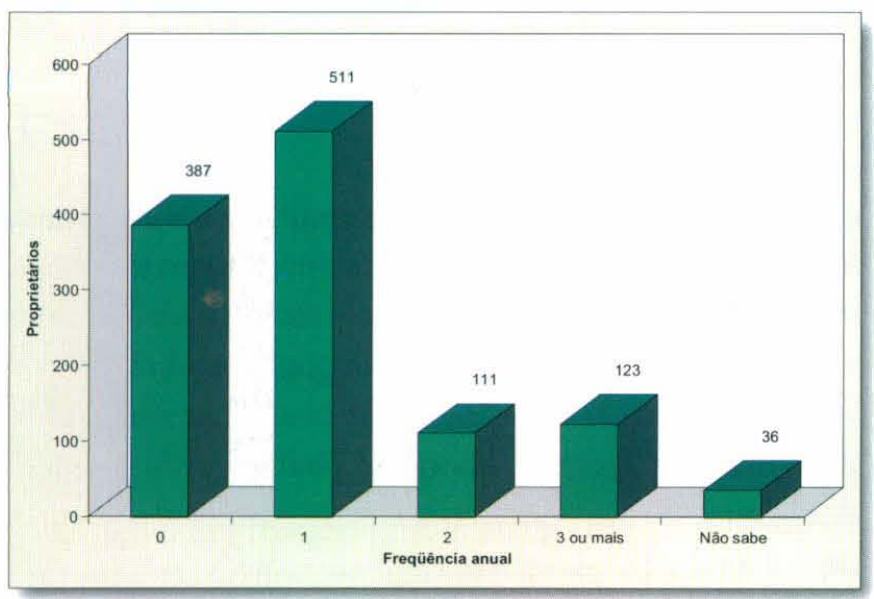

Figura 4 - Frequêencia anual com que os proprietários aplicam ectoparasiticidas em seus cães, de acordo com questionário respondido durante a campanha anual de vacinação anti-rábica Botucatu. 2001

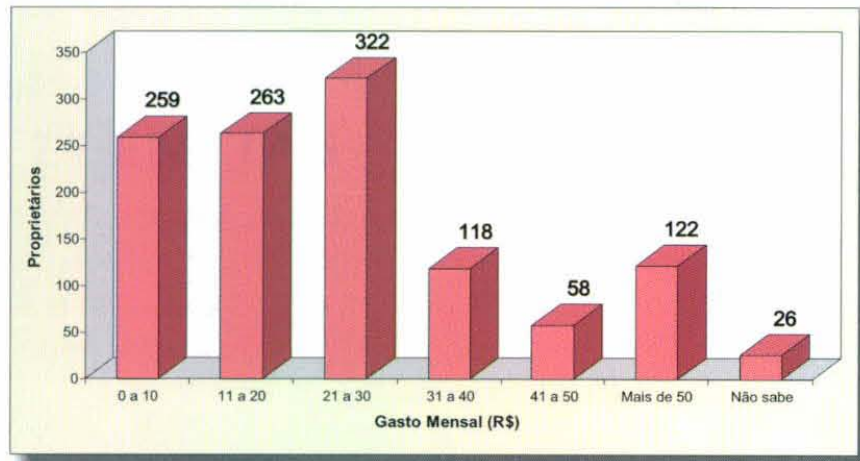

Figura 5 - Gasto mensal médio $(\mathrm{R} \$)$ dos proprietários de cães com seus animais, de acordo com questionário respondido durante a campanha anual de vacinação anti-rábica. Botucatu. 2001.

índices observados nos EUA (152 cães para cada grupo de 100 proprietários), de acordo com estudos da AVMA(WISE; YANG, 1992a). Obviamente, esta diferença está relacionada a fatores culturais e ao tipo de imóvel predominante nas regiões estudadas. Nos cen-

\begin{tabular}{|l|c|c|}
\hline & $n$ & $\%$ \\
\hline Nunca leva ao veterinário & 661 & 56,59 \\
\hline Raramente leva ao veterinário & 322 & 27,57 \\
\hline Leva anualmente ao veterinário & 120 & 10,28 \\
\hline $\begin{array}{l}\text { Leva duas ou mais vezes } \\
\text { por ano ao veterinário }\end{array}$ & 54 & 4,62 \\
\hline Sem resposta & 11 & 0,94 \\
\hline Total & 1168 & 100,00 \\
\hline
\end{tabular}

Quadro 4 - Freqüência com que os proprietários levam seus cães a uma clínica veterinária para consulta, de acordo com questionário respondido durante a campanha anual de vacinação anti-rábica. Botucatu. 2001

\begin{tabular}{|l|c|c|}
\hline & $n$ & $\%$ \\
\hline Muito alto e não pode pagar & 579 & 49,57 \\
\hline Alto, mas pode pagar & 206 & 17,64 \\
\hline Nem alto nem baixo & 276 & 23,63 \\
\hline Baixo & 35 & 3,00 \\
\hline Sem resposta & 72 & 6,16 \\
\hline Total & 1168 & 100,00 \\
\hline
\end{tabular}

Quadro 5 - Opinião dos proprietários com relação ao preço das consultas, em clínicas veterinárias particulares, de acordo com questionário respondido durante a campanha anual de vacinação antirábica. Botucatu. 2001.

tros urbanos e em regiões de maior concentração de edifícios, a tendência é que a relação cão/proprietário seja menor.

Ainda de acordo com os estudos da AVMA, $40,30 \%$ dos proprietários de cães nos EUA também criam gatos, índice quase três vezes superior ao obtido no presente trabalho. Esta diferença está relacionada, principalmente, ao fato de que, nos EUA, a criação de gatos parece estar mais difundida do que no Brasil. Nos EUA, a população de gatos domésticos (59,1 milhões) supera, até a de cães (52,9 milhões) (GEHRKE, 1997).

O fato de mais de $50,00 \%$ dos proprietários terem afirmado que alimentam seus cães exclusivamente com ração comercial representa uma adaptação dos indivíduos às mudanças sociais características da pósmodernidade, em que o tempo dedicado às atividades 
domésticas é cada vez menor. A praticidade e o incremento da qualidade nutricional das rações comerciais têm estimulado cada vez mais os proprietários a optar por este tipo de alimento para os seus animais. A produção brasileira de ração para cães e gatos passou de 220 mil toneladas, em 1994, para mais de um milhão, em 2001 (Jornal O Estado de São Paulo, B5, 17/02/ 2002). O que preocupa, no entanto, é que muitos proprietários preferem comprar as rações mais baratas, as quais nem sempre apresentam uma qualidade nutricional adequada.

Os resultados obtidos no presente estudo alertam para a necessidade urgente de campanhas educativas que mostrem à população em geral os incômodos e danos à saúde pública causados pelas fezes dos animais depositadas nas vias públicas. O recolhimento das fezes dos animais é um hábito raro no Brasil, e a mudança desse paradigma não se dará apenas por meio de medidas legais, mas, principalmente, por um intenso processo educativo.

A campanha de vacinação anti-rábica canina e felina tem sido realizada com êxito há mais de duas décadas, em Botucatu, graças à parceira entre Prefeitura e Universidade. A campanhaé de fundamental importância para o controle da queé a mais importante das zoonoses.

Entretanto, a maior parte dos proprietários, em especial os mais carentes, desconhece a necessidade de aplicação de outras vacinas além da anti-rábica. Este fato contribui para uma elevada prevalência de doenças infecto-contagiosas importantes e passíveis de prevenção vacinal, como a cinomose, a parvovirose e a leptospirose, esta última de interesse também para a saúde pública.

Se, por um lado, o êxito epidemiológico da campanha de vacinação anti-rábica é imprescindível para quebrar o elo de transmissão do vírus rábico pelos cães, em áreas urbanas, por outro, induz as pessoas a ter a falsa impressão de que levar o seu cão, anualmente, para ser vacinado na campanha é sua única responsabilidade para com a saúde deste.

Segundo a AVMA, 82,30\% dos proprietários norte-americanos levaram seus cães para serem consultados, em uma clínica veterinária, pelo menos uma vez, em 1991 (WISE; YANG, 1992b), índice este mais de cinco vezes superior ao obtido no presente inquérito. $\mathrm{O}$ aspecto econômico é um dos principais fatores que contribuem para esta realidade. Segundo os entrevistados no presente estudo, o preço de uma consulta veterinária quase sempre é incompatível com o seu poder aquisitivo.

Pode-se concluir que, de uma forma geral, poucos proprietários entrevistados zelam pela saúde e bemestar dos seus cães, fato este evidenciado, por exemplo, pela subutilização de vacinas, vermífugos e ectoparasiticidas. Estes dados mostram a displicência e despreparo dos proprietários, o que pode estar relacionado à condição socioeconômica da população estudada e também a fatores culturais, haja vista que, no Brasil, muitas vezes, os animais de companhia são tratados como meros objetos de lazer.

Ao mesmo tempo que alguns proprietários gastam centenas de reais, mensalmente, com acessórios, brinquedos, banhos, serviços veterinários e ração para os cães, $45,70 \%$ dos proprietários amostrados gastam menos de R \$20,00/mês com seus animais. Este valor, segundo trabalho realizado por Souza et al. (2001), é insuficiente para oferecer os cuidados mínimos necessários para a promoção da saúde e bem-estar dos cães.

Medidas legais como a que entrou em vigor no Município de São Paulo, em fevereiro último, obrigando os proprietários a cadastrar seus animais e estabelecendo multas para aqueles que não recolhem as fezes dos animais em vias públicas, fomentam a discussão, porém não são suficientes para quebrar determinados paradigmas relacionados à posse responsável de cães e gatos.

Infelizmente, os números observados no presente estudo só podem ser mudados por um eficiente programa de educação continuada em saúde. Apenas com o desenvolvimento econômico da Nação, a melhoria da distribuição de renda e um processo educativo que permita a internalização dos conceitos de posse responsável de animais de companhia os números poderão ser melhorados.

\section{AGRADECIMENTO}

À Secretaria de Saúde da Prefeitura Municipal de Botucatu. 


\section{SUMMARY}

Aspects related to owner dog care were investigated by questionnaire in Botucatu, SP, during the $33 \mathrm{rd}$ annual anti-rabies vaccination campaign. From the 1168 owners interviewed, $67.98 \%$ were not aware of the need for vaccines other than anti-rabies; $32.11 \%$ did not treat their dogs annually with vermifuges; and $76.89 \%$ used ectoparasiticides at the most once a year. Of the 120 owners that exercise their dogs on the street, only one collects the feces. In relation to feeding, $50.09 \%$ receive only commercial products. Results showed 187 dogs for every 100 owners. With regard to veterinary assistance, $56.59 \%$ never take their dogs to a clinic; $49.57 \%$ reported not being able to afford a consultation. For monthly cost, $44.69 \%$ reported spending less than R $\$ 20.00$ per month. Data from this study indicate that most owners do not provide the basic minimum care needed for a dog's health and well-being, this can have an impact on public health. A country's socioeconomic development and an efficent and a continuing health education program which allows a full understanding about responsible ownership of companion animals are major factors in the improvement of animal well-being and public health.

Key words: Responsible ownership. Animal health. Public health. Dog.

\section{RESUMEN}

Se investigaron aspectos relacionados con los cuidados que los propietarios de perros dispensan a sus animales en la municipalidad de Botucatu, Estado de São Paulo, mediante la realización de una encuesta. Se entrevistaron 1168 personas durante la $33^{\mathrm{a}}$ campaña anual de vacunación antirrábica. De este total, el 67,98\% (794/1168) desconoce la necesidad de aplicar otras vacunas en sus perros, además de la antirrábica. Se constató que el 32,11\% (388/1168) de los propietarios no desparasitan a sus perros anualmente y el $76,89 \%(898 / 1168)$ utilizan ectoparasiticidas como máximo una vez al año. De los 120 dueños que llevan sus perros a defecar en la vía pública, sólo un $(0,83 \%)$ recoge las heces. Con relación a la alimentación de los animales, el 50,09\% (585/1168) es alimentado sólo con ración comercial. Los resultados revelaron que existen 187 perros para cada grupo de 100 propietarios. En lo que respecta al servicio veterinario, el 56,59\% (661/1168) de los entrevistados jamás llevaron a sus perros a una consulta en una clínica veterinaria, siendo que el $49,57 \%$ (579/ 1168) dijo que no tenía posibilidad de pagar una consulta. Cuando se les preguntó sobre el gasto mensual que tienen con sus perros, el 44,69\% (522/1168) de los propietarios respondieron que gastan menos de $\mathrm{R} \$ 20,00 /$ mes. Los datos obtenidos en el presente trabajo indican que la mayoría de los propietarios no dispensa los cuidados mínimos necesarios para promover la salud y el bienestar de sus perros, lo que puede traer consecuencias también en la salud pública. El desarrollo socioeconómico del país y un proceso eficiente de educación continua en salud que permita la incorporación de los conceptos de posesión responsable de mascotas son factores indispensables para mejorar el bienestar animal y, por consiguiente, la salud pública.

Palabras clave: Posesión responsable. Salud animal. Salud pública. Perro. 


\section{REFERÊENIAS}

GEHRKE, B. C. Results of the AVMA survey of US pet-owning households on companion animal ownership. Journal of the American Veterinary Medical Association, v. 211, n. 2, p.169$70,1997$.

\section{INSTITUTO BRASILEIRO DE GEOGRAFIAEESTATÍSTICA.}

Contagem da população 2000. Brasília, 2000. Disponível em http://www.ibge.net/home/estatistica/ populacao/censo2000/ universo.php>. Acesso em: 11 abr. 2002.

SOUZA, L. C. et al. Associação homem-animal: reflexos na economia. Revista de Educação Continuada CRMV-SP, v. 4, n. 1, p. $62-65,2001$.

WISE, J. K.; YANG, J. J. Veterinary service market for companion animals, 1992. Part I: companion animal ownership and demographics. Journal of the American Veterinary Medical Association, v. 201, n. 7, p. 990-992, 1992a.

WISE, J. K.; YANG, J. J. Veterinary service market for companion animals, 1992. Part II: veterinary service use and expenditures. Journal of the American Veterinary Medical Association, v. 201, n. 8, p.1174-1176, 1992b. 